\title{
Proposição de um modelo de estratégia de marketing em loja agropecuária
}

O agronegócio brasileiro é um dos setores que mais se destaca na economia do país, contribuindo para a geração de emprego e renda em todos os seus segmentos, denominados "antes, dentro e depois da porteira". Sob este enfoque, os negócios voltados para o setor agropecuário tornam-se mais competitivos mediante a implementação de ferramentas de gestão à rede de negócios, sobre os quais se relacionam. Neste sentido, o presente estudo, apresenta um planejamento estratégico para a empresa de produtos agropecuários Agro Vida, situada no município de Iporá no Estado de Goiás, tendo como objetivo identificar aspectos gerenciais que contribuam em termos de competitividade. Metodologicamente, a pesquisa caracteriza-se como exploratória, com abordagem qualitativa, por meio de observação simples, entrevistas e atividades in loco, que subsidiaram a identificação de potencialidades e gargalos presentes no empreendimento, assim como a realização de pesquisa bibliográfica sobre os conceitos inerentes ao planejamento estratégico, marketing e comunicação visual. Através dos resultados foi possível verificar a carência em relação a identificação visual da marca nas embalagens de $5 \mathrm{~kg}$ das rações para aves, sendo sugerido uma ação de adequação dessas embalagens.

Palavras-chave: Agronegócio; Estratégias; Processos de Gestão.

\section{Proposition of a marketing strategy model in an agricultural store}

Brazilian agribusiness is one of the sectors that most stands out in the country's economy, contributing to the generation of jobs and income in all its segments, called "before, inside and after the gate". Under this approach, businesses focused on the agricultural sector become more competitive through the implementation of management tools to the business network, to which they relate. In this sense, the present study presents a strategic plan for the agricultural products company Agro Vida, located in the municipality of Iporá, with the objective of identifying managerial aspects that contribute in terms of competitiveness. Methodologically, the research is characterized as exploratory, with a qualitative approach, through simple observation, interviews and on-site activities, which supported the identification of potentialities and bottlenecks present in the enterprise, as well as the performance of bibliographic research on the concepts inherent to the project. Strategic planning, marketing and visual communication. Through the results, it was possible to verify a lack in the designer and identification of the brand in the packages of $5 \mathrm{~kg}$ of the rations for birds, being suggested an action of adaptation of these packages.

Keywords: Agribusiness; Strategies; Management Processes.

Topic: Marketing e Estratégias Mercadológicas

Reviewed anonymously in the process of blind peer.

Maria Gláucia Dourado Furquim (ic)

Instituto Federal Goiano, Brasil

http://lattes.cnpq.br/2681775689273863

http://orcid.org/0000-0001-7823-9546

maria.furquim@ifgoiano.edu.br

Márcia Brito de Oliveira (ib

Instituto Federal Goiano, Brasil

http://lattes.cnpq.br/9467251342756511

http://orcid.org/0000-0003-0121-3692

icsj10@gmail.com

José Carlos de Sousa Júnior (iD

Instituto Federal Goiano, Brasil

http://lattes.cnpq.br/9146562480275155

http://orcid.org/0000-0003-2578-8140

josecarlos.junior@ifgoiano.edu.br
Received: 09/01/2021

Approved: 21/03/2021

\author{
Daniela Cabral de Oliveira (D) \\ Instituto Federal Goiano, Brasil \\ http://lattes.cnpq.br/2113470352941981 \\ http://orcid.org/0000-0002-9647-933X \\ jcsj10@gmail.com \\ Paulo Alexandre Perdomo Salviano (iD) \\ Instituto Federal Goiano, Brasil \\ http://lattes.cnpq.br/2777819799992125 \\ http://orcid.org/0000-0003-2312-4826 \\ jcsj10@gmail.com \\ Juliano de Caldas Rabelo (iD \\ Instituto Federal Goiano, Brasil \\ http://lattes.cnpq.br/5054768054817475 \\ http://orcid.org/0000-0003-3741-4488 \\ jcsj10@gmail.com
}

\section{Referencing this:}

FURQUIM, M. G. D.; OLIVEIRA, M. B.; SOUSA JÚNIOR, J. C.; OLIVEIRA, D. C.; SALVIANO, P. A. P.; RABELO, J. C.. Proposição de um modelo de estratégia de marketing em loja agropecuária. Revista Brasileira de Administração Científica, v.12, n.1, p.40-51, 2021. DOI: http://doi.org/10.6008/CBPC2179-684X.2021.001.0004 


\section{INTRODUÇÃO}

O agronegócio brasileiro tem adquirido cada vez mais relevância na promoção do desenvolvimento econômico nacional, contribuindo para a geração de emprego, renda e riqueza, de forma direta e indireta, reforçando a aptidão agrícola do país. O setor contribuiu em 2019 com participação de 21,9\% no Produto Interno Bruto (PIB) total, se destacando como o maior exportador mundial de café, açúcar e cana-de-açúcar; segundo maior exportador de carne bovina e o maior exportador de carne de frango, sendo também o quarto do mundo na venda internacional de carne suína.

Por conseguinte, esse setor da economia compreende uma cadeia de atividades descritas em segmentos denominados "antes, dentro e depois da porteira", que inclui o fornecimento de insumos e suprimentos, a própria produção agrícola, transformação e distribuição, além do desenvolvimento de tecnologias para estimular todas essas atividades. Para Mendes (2007), todo o sistema envolvido que engloba os elos da cadeia do agronegócio levou a uma completa mudança de concepção nos negócios rurais, sendo um ponto estratégico na empresa: a criação de valor por meio de um produto/serviço único e diferenciado, que garanta a satisfação dos clientes.

No Estado de Goiás, o setor agropecuário responde por parcela inferior na formação do PIB, mas possui significativa relevância para a economia goiana, sendo que é a partir dele, que deriva a "agroindústria, uma das atividades mais pujantes do estado, quer seja na produção de carnes, derivados de leite e de soja, molhos de tomates, condimentos e outros itens da indústria alimentícia, bem como na produção de açúcar e geração de energia" (IMB, 2019). Sob este enfoque, os negócios voltados para o segmento agrícola se tornam mais competitivos mediante a implantação de ferramentas de gestão à rede de negócios e aos complexos agroindustriais com as quais se relacionam. Destacando-se as estratégias de marketing como recurso para atingir os objetivos pretendidos pelas organizações, o que de acordo com Morgan (2019) "esforços de marketing de uma empresa impactam seu mercado e desempenho econômico através da formulação e implementação de padrões específicos de implementação de recursos projetado para atingir objetivos de marketing em um mercado-alvo".

Deste modo, a presente pesquisa apresenta um planejamento estratégico para a Loja Agropecuária Agro Vida, com base na observação das fronteiras encontradas, a luz da estratégia de marketing, considerando a relevância dos empreendimentos agropecuários no fornecimento de insumos. Conforme corrobora Andrews (1994), reconhecer onde uma empresa pode operar de forma bem-sucedida, possibilita aos gestores entender com o sucesso e o fracasso de suas políticas instituídas.

\section{REVISÃO TEÓRICA}

\section{Abordagem conceitual sobre Planejamento estratégico empresarial}

Para que uma empresa possa alcançar os objetivos esperados é importante que ela tenha um modelo de gestão diferenciada. Segundo, Chiavenato (2007) a Administração consiste no processo de planejar, organizar, dirigir e controlar uma organização, por meio de ações sistematicamente definidas, e adoção de 
instrumentos como o planejamento estratégico, que proporciona aos gestores uma visão abrangente das oportunidades e ameaças existentes no mercado competitivo. Sendo conceitualmente definido:

Planejamento estratégico é o processo administrativo que proporciona sustentação metodológica para se estabelecer a melhor direção a ser seguida pela empresa, visando ao otimizado grau de interação com os fatores externos - não controláveis- e atuando de forma inovadora e diferenciada. (OLIVEIRA, 2012)

A gestão estratégica compreende a criação de uma visão clara de toda a organização - desde o mais alto nível da pirâmide organizacional até o nível operacional - contemplando sua missão, visão e desenvolvimento de planos e estratégias que levem à realização dos objetivos pretendidos. Segundo um autor, para que as organizações consigam realizar o acompanhamento das estratégias, são necessários indicadores que permitam aos gestores manter o foco nos resultados de curto e longo prazo.

Planejamento é uma ferramenta administrativa, que permite os gestores avaliar decisões futuras do que e como deve ser feito, evitando riscos desnecessários que venham a prejudicar a organização, e nesse sentido possibilitando alcançar seus objetivos. Nesse contexto, no nível institucional de uma empresa encontra- se o planejamento estratégico, que segundo Chiavenato (2007) "planejamento estratégico é o planejamento mais amplo e envolvente e abrange toda a organização como um sistema único e aberto", ou seja, umprocesso gerencial que permite definir um rumo a ser seguido com a colaboração de todos na empresa (MATIAS, 2011).

Ademais, um planejamento estratégico empresarial refere-se a estratégia adotada em âmbito de organização com fins lucrativos, ou seja, retorno acima do investimento feito. Se trata de uma metodologia utilizada para estabelecer metas, mobilizar ações, que pretenda atingir seus objetivos conforme planejado. O mercado competitivo exige mudanças constantes, e as empresas precisam traçar planos e ações para estar à frente dos concorrentes. De acordo com a Figura 1, são apresentadas as etapas da metodologia padrão para elaboração de um Planejamento Estratégico Empresarial segundo abordagem de Mintzberg.

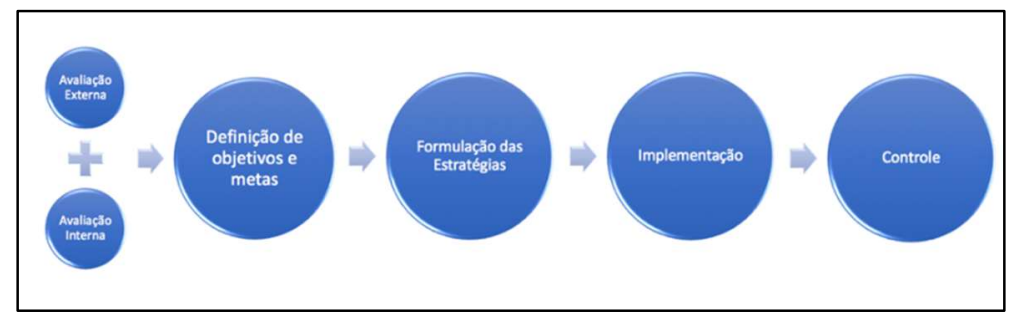

Figura 1: Etapas do Planejamento Estratégico Empresarial. Fonte: Adaptado Migliato et al. (2003).

Para um autor, o planejamento estratégico consiste no direcionamento para um futuro que se almeja moldar favoravelmente a quem o elabora, sendo igualmente importante à execução do plano, no transcorrer do tempo, a partir de tem duas perspectivas: a de um plano e a da execução deste plano.

A estratégia empresarial está centrada no fato do que a empresa deverá fazer para alcançar diferenciais competitivos sustentáveis (CHIAVENATO, 2007). Segundo, Borges Júnior et al. (2000) “a ideia de estratégia incorpora componentes qualitativos, afastando-se do conceito inicial de algo estático e rígido e aproximando-se de um conhecimento profundo sobre a relação da organização e seu meio ambiente". Para um autor, as estratégias estão condicionadas pelo ambiente competitivo, no qual são definidos os padrões 
de concorrência e capacitação dos recursos internos das firmas. Daí a importância das lojas agropecuárias se atentarem na busca por informações de mercado e no estabelecimento de parcerias que contribuam para o seu desenvolvimento.

Do mesmo modo, Batalha (2001) pontua que "a estratégia de uma firma deve permitir-lhe influenciar a dinâmica concorrencial da cadeia de produção, com o objetivo de conseguir vantagens competitivas". Assim, a elaboração e implantação do planejamento estratégico deve envolver ferramentas capazes de proporcionar uma visualização sistêmica da empresa, bem como o delineamento de ações que garantam aumento na eficiência dos processos realizados.

\section{Análise SWOT: definições}

A sigla SWOT é formada pelas iniciais das palavras strengths (forças), weaknesses (fraquezas), opportunities (oportunidades), e threats (ameaças), em resumo, é usada para avaliar os pontos fortes, fracos, oportunidades e ameaças de uma organização. Ela é retratada como uma matriz de quatro células que permitem expor claramente os aspectos analisados e fazer cruzamentos entre as informações obtidas para desenvolver vantagens competitivas, ou realizar ajustes internos (PRIDE et al., 2015). De acordo com Friedrichsen et al. (2017) a estrutura SWOT possibilita o levantamento dos diferentes fatores organizacionais e seu ambiente. Para Carvalho et al. (2010) “[...] tem como objetivo reconhecer as limitações, maximizando os pontos fortes da organização enquanto monitora oportunidades e ameaças no ambiente competitivo".

Segundo Santini (2011) "pontos fortes e pontos fracos são variáveis internas e controláveis pela organização, já as ameaças e oportunidades, são variáveis externas à organização, provenientes do ambiente organizacional, sobre as quais não se tem controle". De acordo com Pride et al. (2015) a matriz SWOT pode ser compreendida da seguinte forma:

Pontos fortes referem-se às vantagens competitivas ou competências centrais, que referem à empresa uma superioridade sobre as outras no atendimento das necessidades de seus mercados -alvo.

Pontos fracos são limitações que uma empresa enfrenta no desenvolvimento ou implementação de uma estratégia de marketing.

Oportunidades referem -se às condições favoráveis no ambiente que podem recompensar uma organização caso sejam postas em prática.

Ameaças por outro lado, são as barreiras que impedem a organização de alcançar seus objetivos.

Para Matias (2011) "a matriz SWOT que começou a ser desenvolvida nos anos 60, nas escolas americanas de administração, tem como objetivo definir estratégias para manter pontos fortes, reduzir a intensidade de pontos fracos, aproveitando as oportunidades e proteger-se das ameaças"; dessa forma, temse uma visão de um todo, onde se define os processos e objetivos a serem alcançados, possibilitando traçar o tipo de estratégia a ser seguida. Segundo o autor, é fundamental considerar as especificidades de cada organização, reconhecendo o que a torna única na percepção do consumidor, ou seja, implementando uma estratégia de "criação de valor". 


\section{Marketing e a importância da comunicação visual}

Segundo Kotler et al. (2006): “Marketing envolve a identificação e a satisfação das necessidades humanas e sociais. Para defini-lo de uma maneira bem simples, podemos dizer que ele supre necessidades lucrativamente". Segundo Morgan (2012) as estratégias de marketing estão vinculadas ao desempenho dos negócios, considerando o grau de competição e a estrutura do mercado no qual se opera. Para Coelho et al. (2015) o objetivo do marketing evoluiu, de uma condição de oferta de produto/serviço entre fornecedores e consumidores, para um processo de trocas que estabeleça um relacionamento de longo prazo com os clientes, parceiros e sociedade em geral. Por sua vez, "a estratégia de marketing é amplamente aceita como o conceito principal do campo do marketing estratégico".

Desta forma, as ações de marketing influenciam no desempenho organizacional, por representar a capacidade da empresa em estabelecer um relacionamento lucrativo de longo prazo com grupos de clientes (TAKAHASHI et al., 2017). Corrobora com esse entendimento Vargas et al. (2020), ao expor que "[...] as relações que a empresa tem com seus consumidores são fortalecidas pela capacidade de reter seus clientes, o que é alcançado por meio de habilidades de marketing".

Assim, uma ação eficaz de marketing começa com um planejamento de um produto/serviço, que leva a atender as necessidades dos clientes, e que se apresente de forma competitiva, refletindo a capacidade da empresa em termo competitivo (FARIAS et al., 2015). Sob essa perspectiva, as embalagens exercem influência mercadológica nas estratégias de vendas, por representarem o primeiro contato visual do consumidor/cliente com o produto, despertando o interesse e induzindo a aquisição. Para isso, é fundamental investir em uma identidade que represente os valores do produto/serviço.

A comunicação visual apresenta-se como uma importante estratégia para que a empresa consiga se diferenciar no segmento com a utilização de elementos visuais como forma de linguagem, tais como: desenhos, imagens, gráficos, vídeos, fotos, entre outros. Assim sendo, as marcas que adequadamente empregam esse modelo de comunicação fortalecem a sua identidade visual, ou seja, a marca tem um jeito único de se expressar visualmente com os consumidores. Para Cardoso (2012) “as comunicações de marketing ligam uma empresa a vários grupos que podem ser clientes atuais e potenciais nas diferentes situações".

Pride et al. (2015) explicam que a embalagem pode representar um componente essencial de estratégia de marketing: “Uma nova tampa ou fecho, uma caixa ou invólucro melhores, ou um recipiente mais conveniente, podem dar uma vantagem competitiva a um produto"; portanto, embalagens inovadoras aumentam a qualidade de um produto". Através das embalagens as empresas conseguem direcionar sua estratégia de vendas por meio das informações do designer e cores contidas nelas reforçando os atributos do produto. As embalagens estão cada vez mais se tornando um meio de divulgação que conseguem proporcionar que o esforço de venda se torne supérfluo; as embalagens diferenciadas conseguem se destacar e sobressair aos seus concorrentes sem a necessidades de baixar o preço dos produtos. Por exemplo, embalagens bem desenhadas contribuem no reconhecimento da marca (CARDOSO, 2012). 


\section{METODOLOGIA}

Para a realização da pesquisa foi utilizado o método qualitativo, que segundo Pinheiro (2010) tratase de um método em que a "pesquisa é aplicada para o levantamento de hipóteses e seus métodos de coleta de dados e análise são apropriados para a pesquisa exploratória". Os procedimentos metodológicos foram realizados a revisão bibliográfica em artigos científicos e sites acadêmicos, relacionados ao tema proposto, entrevista e observação simples.

As atividades in loco da pesquisa foram feitas na loja agropecuária Agro Vida situada na cidade de Iporá-GO, à técnica utilizada para a pesquisa foi realizada por observação simples e entrevista com o proprietário do estabelecimento. De acordo com o autor Rodrigues (2006): “A observação consiste em uma técnica de coleta de dados a partir da observação e do registro, de forma direta, do fenômeno ou fato estudado". Ainda segundo o autor o método de "entrevista é a técnica utilizada pelo pesquisador para obter informações a partir de uma conversa orientada com o entrevistado e deve atender a um objetivo predeterminado". Dessa forma, foram aplicados questionários composto por perguntas abertas para os sócios da empresa, possibilitando a obtenção das informações para a realização do presente estudo.

A empresa analisada é fornecedora de insumos do setor agropecuário, e isso já requer uma maior atenção em termos de mercado e gestão para sua manutenção e consolidação no setor. A empresa possui um comportamento com viés estratégico, por possuir um portfólio de produtos diversificados e especialmente marca própria na formulação de rações. Cabe destacar que, em boa parte dos municípios goianos prevalece o exercício de atividades agropecuárias, e no município de Iporá essa realidade não é diferente. Neste sentido, quanto aos objetivos da pesquisa realizou-se um estudo de caso, o que segundo Yin (2005) “Um estudo de caso é uma investigação empírica que investiga um fenômeno contemporâneo dentro de seu contexto da vida real, especialmente quando os limites entre o fenômeno e o contexto não estão claramente definidos".

\section{RESULTADOS E DISCUSSÃO}

\section{Caracterização da empresa}

O estudo em questão, consiste na utilização de ferramenta de gestão, numa perspectiva estratégica consoante abordagem do planejamento estratégico empresarial (PEE) e objetivos da pesquisa. A primeira etapa compreende a realização do diagnóstico organizacional e caracterização da empresa objeto de estudo. Diante do contexto apresentado, a loja agropecuária Agro Vida, está localiza no município de Iporá-GO, e iniciou suas atividades em 2002, sendo formada por dois sócios, sua atuação é voltada para a vendas de produtos agropecuários, nutrição animal e medicamentos.

A empresa tem como missão oferecer produtos de qualidade para atender as necessidades dos produtores rurais, e como visão, ser referência na produção e comercialização de ração específica para cada período de desenvolvimento das aves e bovinos. A partir da análise realizada, podemos definir que a missão é a razão de ser de uma organização, o propósito pelo qual ela existe. A visão de uma empresa responde o que 
ela deseja ser no futuro, ou seja, onde ela pretende chegar.

Conforme elucida Chiavenato (2009), “A missão define o papel da organização dentro da sociedade em que está envolvida e significa sua razão de ser e de existir", o mesmo autor esclarece que a visão pode ser intensamente inspiradora e explicar a razão pela qual "as pessoas dedicam a maior parte de seu tempo para o sucesso da sua organização. Quanto mais a visão de negócios estiver alinhada aos interesses dos parceiros, maior será a possibilidade de atingir seus propósitos".

Por sua vez, o portfólio de produtos da loja agropecuária são medicamentos veterinários para animais de grande porte e pets, ferramentas em geral que auxiliam no trabalho rural, acessórios para os animais como selas, arreios, ferraduras, mantas, cabrestos, acessórios para o produtor como: chapéus, botas, botinas, cintos, bainhas, luvas, rações para bovinos, suínos e aves, e acessórios para pets.

O público-alvo da empesa é constituído por pequenos produtores da região. Conhecer o públicoalvo, possibilita direcionar serviços e produtos que melhor atenda aos clientes. Barney (1991) menciona que a vantagem competitiva sustentável (SCA) deve ser estabelecida a partir da análise dos recursos financeiro, humano e organizacional denominado "recursos da firma", isso inclui todos os ativos, capacidades, processos organizacionais, atributos da empresa, informações, conhecimentos e outros, controlados por uma empresa e que a permite conceber e implementar estratégias que melhorem sua eficiência e eficácia. De acordo com o autor, as firmas diferem essencialmente em seus modos de operar, porque cada uma delas possui um agrupamento singular de recursos.

A estrutura organizacional de uma empresa é constituída por níveis conceitualmente definidos segundo Chiavenato (2009) em "Nível Institucional corresponde ao nível mais elevado da organização. [...] Nível intermediário corresponde à linha do meio campo e é constituído da média administração, \{...]. O nível operacional envolve a programação e execução das atividades cotidianas da empresa". Os níveis organizacionais (hierárquicos), da empresa são representados pelos proprietários que estão no nível institucional, os quais elaboram o planejamento estratégico, e definem a atuação e direcionamento das ações em sua totalidade. O nível tático é de competência do supervisor de vendas, sendo que o mesmo é veterinário na loja, e responsável por todos medicamentos fornecidos pela empresa, assim como a prestação de serviço veterinário e formulação de ração; no nível tático encontra-se também o supervisor de produção da fábrica, ficando sob sua responsabilidade, todo o processo da produção e controle das encomendas dos produtores; por fim, no nível operacional estão os colaboradores da loja agropecuária e também da fábrica de ração, eles realizam todas as atividades rotineiras, atendimento ao cliente, limpeza, organização, recebimento e despacho de mercadorias, e são responsáveis pela entrega de produtos na cidade.

\section{Planejamento estratégico para empresa agropecuária Agro Vida}

Fazer uma análise do ambiente geral é fundamental para o planejamento estratégico, dessa forma é possível averiguar as potencialidades e vulnerabilidades da organização. De acordo com Oliveira (2012) "o diagnóstico estratégico corresponde à primeira fase do processo de planejamento estratégico e procura responder o questionamento básico: qual a real situação da empresa quanto aos seus aspectos internos?", 
analisando assim, o que a ela apresenta de vantajoso, regular ou ruim, quanto ao seu processo administrativo. Nas palavras de Pereira (2012) as decisões no âmbito das empresas devem considerar a utilização adequada dos diferentes recursos (tecnológicos, físicos, financeiros e humanos) no sentido de reduzir os gargalos e maximizar o uso das oportunidades percebidas.

Uma ferramenta comumente utilizada para a realização do diagnóstico organizacional é a elaboração da Matriz SWOT, pois ela permite avaliar aspectos relevantes para o planejamento de uma empresa, seu principal objetivo é dar um diagnóstico estratégico de uma organização, em que é possível analisar fatores positivos e negativos que visam alcançar os objetivos propostos. Conforme elucida Chiavenato (2007), "na verdade, trata-se de uma tabela de dupla entrada na qual nas linhas estão as forças e fraquezas organizacionais, e nas colunas as oportunidades e ameaças ambientais". Nesse sentido a construção da matriz permite analisar cada ponto identificado dos ambientes (interno e externo) como instrumental para a tomada de decisão, alinhado aos aspectos levantados no diagnóstico, conforme apresentado no quadro 1.

Quadro 1: Matriz SWOT da empresa Agro Vida.

\begin{tabular}{|c|c|}
\hline Forças & Fraquezas \\
\hline $\begin{array}{l}\text { - Bom atendimento; } \\
\text { - Fábrica própria de ração; } \\
\text { - Localização da empresa; } \\
\text { - Satisfação dos clientes; } \\
\text { - Diversidade de produtos; } \\
\text { - Prestação de serviço (calcário); } \\
\text { - Prestação de serviço (veterinário); } \\
\text { - Organização da loja e limpeza; } \\
\text { - Opção de pagamento no cartão e desconto a } \\
\text { vista; } \\
\text { - Entrega em domicílio na cidade sem custo } \\
\text { adicional; } \\
\text { - Controle de estoque; } \\
\text { - Diferencial da marca. }\end{array}$ & $\begin{array}{l}\text { - Venda a prazo em notas promissórias (risco de inadimplência); } \\
\text { - Ausência de propagandas nas rádiose mídias locais (estratégias de marketing); } \\
\text { - Embalagem de 5kg, sem descrição do produto e marca; } \\
\text { - Número insuficiente de colaboradores e acúmulo de funções; } \\
\text { - Centralização na tomada de decisão. }\end{array}$ \\
\hline Oportunidades & Ameaças \\
\hline $\begin{array}{l}\text { - Crescimento da demanda por produtos/insumos } \\
\text { agrícolas; }\end{array}$ & $\begin{array}{l}\text { - Empresas concorrentes; } \\
\text { - Crise econômica; } \\
\text { - Atraso dos fornecedores; } \\
\text { - Logística. }\end{array}$ \\
\hline
\end{tabular}

Conforme observado no quadro 1 , verifica-se o predomínio dos pontos positivos identificados internamente na empresa estudada, sinalizando empreendimento. Já os pontos negativos precisam ser avaliados e minimizados, especialmente ao considerarmos que um dos gargalos identificados na loja agropecuária foi sugerido adequações na embalagem de um dos produtos comercializado na empresa. Para Kotler et al. (2006): “O importante é as empresas reconhecerem que esses itens possuem diferentes potenciais para ter preços maiores ou receber mais publicidade, a fim de aumentar sua venda, sua margem ou as duas coisas". Para Harrigan et al. (2012), as ações de marketing que as pequenas empresas adotam, são diferentes das grandes organizações, dada a realidade de cada empreendimento, sendo majoritariamente pautado no relacionamento com o cliente.

Neste sentido, de acordo com a etapas propostas na figura 1 que apresenta a metodologia para elaboração do planejamento estratégico empresarial verificou-se: a) Construção da Matriz SWOT: (quadro 1) 
que sinaliza a predominância de pontos positivos internamente, em detrimento as restrições micro e macro ambiental; b) Definição dos objetivos e metas: a empresa tem como meta aumentar sua participação no mercado em média de $5 \%$ ao ano, já seu objetivo é proporcionar melhores resultados econômicos com as vendas das rações que são formuladas na própria fábrica; c) Formulação das estratégias: refere-se à adoção de estratégia de marketing (comunicação visual); d) Implementação: nesta fase foi elaborada uma embalagem mais adequada (ração de $5 \mathrm{~kg}$ para aves), com a utilização de elementos visuais que remetam as especificidades do produto e reforço da marca; e) Controle: feito isso a empresa deve acompanhar os resultados em termos da percepção do cliente em relação a apresentação do produto e volume de vendas após a adoção da nova embalagem.

Nesse contexto foi sugerido uma ação estratégica de adequação das embalagens de $5 \mathrm{~kg}$ das rações para aves. Atualmente a empresa trabalha com dois formatos de embalagens a de $40 \mathrm{~kg}$ e de $5 \mathrm{~kg}$, sendo que a sacaria de $40 \mathrm{~kg}$ apresenta um design com a logomarca bem visível, por sua vez, a embalagem de $5 \mathrm{~kg}$, não apresenta atributos que venha a chamar a atenção do consumidor, ou reforce as particularidades do produto e da marca, conforme apresentado na figura 2.
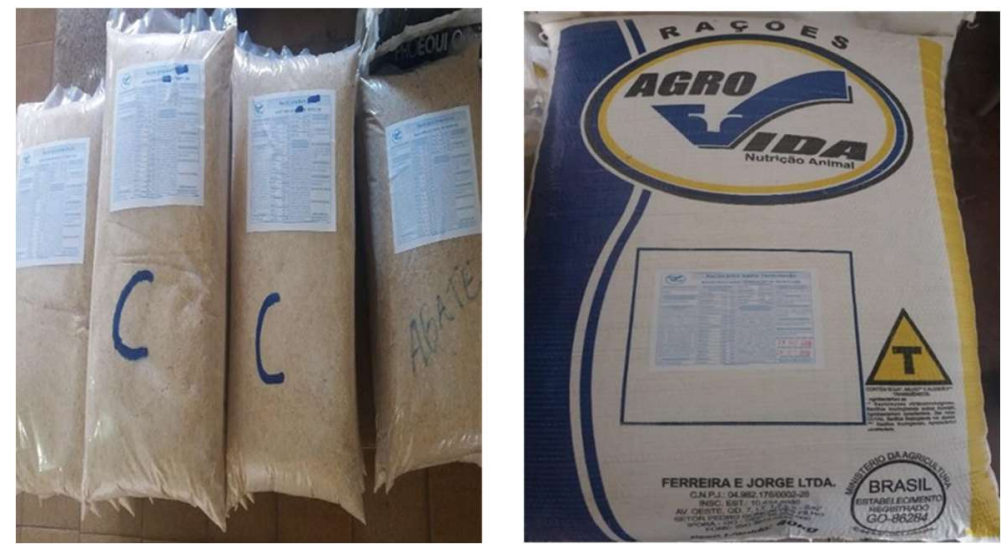

Figura 2: Comparativo entre embalagens de ração de $5 \mathrm{~kg}$ e $40 \mathrm{~kg}$

Neste sentido, Cardoso (2012) aponta que "na comunicação visual, o designer está associado à identificação visual de uma empresa e ao tratamento gráfico adequado às características de certo produto". As embalagens devem ser tratadas e desenvolvidas como um elemento estratégico na divulgação do produto, são através delas que as organizações podem conquistar vantagem competitiva ao reforçar sua marca, por conseguinte, é por meio dos consumidores que as marcas ganham espaço e valor no mercado competitivo.

De acordo com Marques et al. (2020) “Embalagem é um recipiente ou envoltura onde produtos são armazenados de forma temporária, agrupados ou de forma individual, tendo como função principal estender a vida útil de um produto, tornando-o mais viável nos processos de distribuição, consumo e identificação". Ainda segundo os autores, por meio da embalagem o cliente realiza o primeiro contato com o produto, influenciando na decisão de compra sendo, portanto, uma importante estratégia de marketing. Dessa forma, considerando o formato atual das embalagens de rações de $5 \mathrm{~kg}$ para aves, que foi sugerido adequações conforme apresentado na figura 3. 

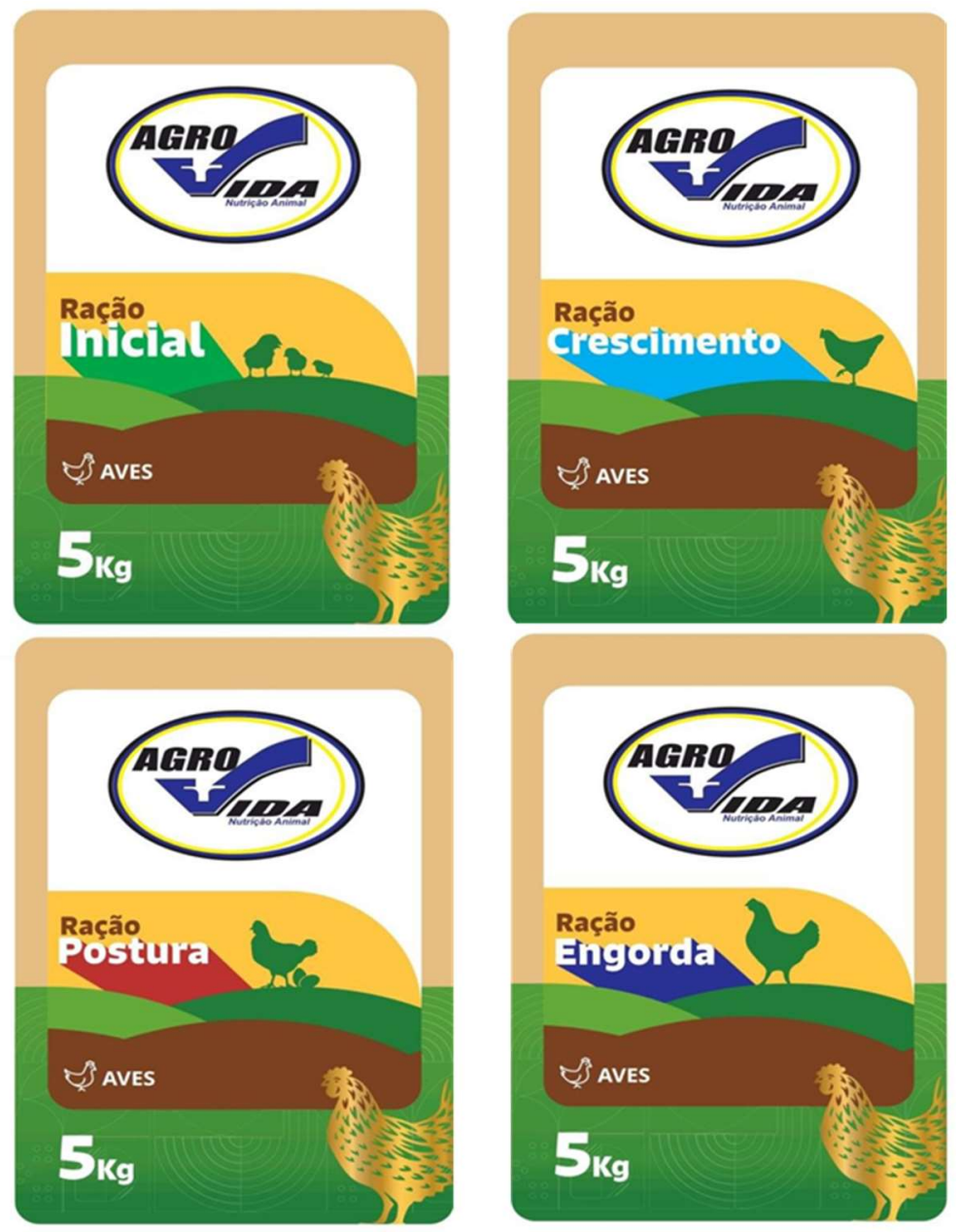

Figura 3: Nova adequação das embalagens de $5 \mathrm{~kg}$.

Como pode ser observado nas embalagens desenvolvidas, os aspectos visuais contemplados, destacam não apenas a marca, como facilita a identificação dos diferentes tipos de ração, para cada etapa do desenvolvimento das aves, para os diferentes sistemas de produção (corte ou postura) evidenciando a importância das mesmas como meio de se estabelecer uma conexão entre o produto e o cliente. Cabe destacar, que as pessoas são movidas pela emoção, e embalagens que contém um design chamativo desperta o interesse para a sua aquisição. Sob esta perspectiva, as embalagens fazem a comunicação e identificação da marca, sendo uma estratégia de vendas nas empresas. Ademais, os aspectos presentes na embalagem contribuem para a definição do valor de um produto, por expressar inicialmente os atributos dos mesmos. Conforme corrobora Varadarajan (2010) a estratégia de marketing consiste em um conjunto de decisões que reflete as escolhas da organização acerca do que será entregue ao consumidor no processo de troca com a organização, considerando os diversos recursos de marketing de marketing na criação, comunicação e / ou entrega de produtos, contribuindo para que a mesma atinja seus objetivos específicos.

\section{CONCLUSÕES}

Esta pesquisa se propôs a apresentar um planejamento estratégico para a Loja agropecuária Agro Vida, com o intuito de identificar particularidades da gestão, que contribuem para a competitividade no mercado. Diante disso, foi elaborado um planejamento estratégico empresarial (PEE) a partir da metodologia 
padrão de Mintzberg, possibilitando ao gestor estabelecer metas e mobilizar ações que almeje atingir seus objetivos conforme planejado.

Diante do levantamento, e através da elaboração da Matriz SWOT que permite analisar cada ponto identificado dos ambientes internos e externos da organização, foi constatado que um dos produtos comercializados na empresa apresenta deficiência no que se refere aos aspectos de design das embalagens de $5 \mathrm{~kg}$ de ração para aves. Dessa forma, foi sugerido uma ação estratégica de adequação dessas embalagens, já que a procura desses produtos possui um volume representativo e é através deles que a empresa tem a oportunidade de crescer no mercado.

O planejamento é uma ferramenta administrativa que permite os gestores tomar decisões futuras do que e como deve ser feito, sendo assim, por trabalharem com marca própria os proprietários da loja tem a autonomia para adequar os próprios produtos. Sendo assim, a ação estratégica que foi sugerida no desenvolvimento das novas embalagens de $5 \mathrm{~kg}$, contemplam informações através do design que foi adotado, onde proporciona uma comunicação visual do produto nas diferentes etapas de desenvolvimento das aves, além de facilitar a identificação do produto destinado a animais de corte e postura.

\section{REFERÊNCIAS}

ANDREWS, K.. The concept of corporate strategy. In: WIT, B.; MEYER, R.. Strategy: process, content, context: an international perspective. St. Paul: West Publishing, 1994.

BARNEY, J. B.. Firm Resources and Sustained Competitive Advantage. Journal of management, v.17, p.99-120, 1991.

BATALHA, M. O.. Gestão Agroindustrial. GEPAI: Grupo de Estudos e Pesquisas Agroindustriais. 2 ed. São Paulo: Atlas, 2001.

BORGES JÚNIOR, A. A.; LUCE, F. B.. Estratégias emergentes ou deliberadas: um estudo de caso com os vencedores do prêmio Top de Marketing da ADVB. RAE - Revista de Administração de Empresas, São Paulo, v.40, n.3, p.36-44, 2000.

CARDOSO, A. T. P. M.. Canais de comunicação de marketing: fundamentos, ferramentas e aplicações. Natal: UnP, 2012.

CHIAVENATO, I.. Administração: teoria, processo e prática. 4 ed. Rio de Janeiro: Elsevier, 2007.

CHIAVENATO, I.. Recursos humanos: o capital humano das organizações. 8 ed. Rio de Janeiro: Elsevier, 2009.

COELHO, R. L. F.; MIRANDA, J. R.; CARMARGO FILHO, A.; FREITAG, M. S. B.; ALMEIDA, M. I. S.. Gestão do marketing em micro e pequenas empresas. Revista de Empreendedorismo e Gestão de Pequenas Empresas, v.4, n.2, 2015.

FARIAS, C.; DUSCHITZ, C.; CARVALHO, G. M.. Marketing aplicado. Porto Alegre: Bookman, 2015.

FRIEDRICHSEN, M.; ZAREA, H.; TAYEBI, A.; SAEED ABAD, F. A.. Estratégias competitivas de comercialização de conhecimento e inovação: uma abordagem de AHP SWOT unificada e FUZZY. Ministro da AD, n.30, p.45-72, 2017. DOI: https://doi.org/10.17230/ad-minister.30.3

HARRIGAN, P.; RAMSEY, E.; IBBOTSON, P.. Entrepreneurial marketing in SMEs: the key capabilities of e-CRM. Journal of Research in Marketing and Entrepreneurship, v.14, n.1, p.40-64, 2012.

IMB. Instituto Mauro Borges de Estatísticas e Estudos Socioeconômicos. Agronegócio Goiano. IMB, 2019.

KOTLER, P.; KELLER, K. L.. Administração de marketing. 12 ed. São Paulo: Pearson Prentice Hall, 2006.

MARQUES, J. F. C.; SOUSA JÚNIOR, J. C.; FURQUIM, M. G. D.; SALVIANO, P. A. P.; RABELO, J. C.. Desenvolvimento de estratégia promocional em um pequeno empreendimento agroindustrial: análise descritiva do modelo adotado pela empresa Leves Castanhas. Pesquisa, Sociedade e Desenvolvimento, v.9, n.7, 2020.

MATIAS, P. J.. Curso de administração estratégica: foco no planejamento estratégico. São Paulo: Atlas, 2011.

MENDES, J. T.. Agronegócio: uma abordagem econômica. São Paulo: Pearson, 2007.

MIGLIATO, A. L. T.; ESCRIVÃO, E. F.. Metodologia do planejamento estratégico empresarial e situacional: deficiências, comparações e contribuições. Rio de Janeiro: ANPAD, 2003.

MORGAN, N. A.. Marketing and business performance. Journal of the Academy of Marketing Science, v.40, n.1, p.102-119, 2012.

MORGAN, N. A.; WHITLER, K. A.; FENG, H.; CHERY, S. Research in marketing strategy. Journal of the Academy of 
Marketing Science, v.47, n.1, p.4-29, 2019.

OLIVEIRA, D. P. R.. Planejamento estratégico: conceitos, metodologia e práticas. 30 ed. São Paulo: Atlas, 2012.

PINHEIRO, J. M.. Da iniciação científica ao TCC: uma abordagem para os cursos de tecnologia. Rio de Janeiro: Ciência moderna, 2010.

PRIDE, W. M.; FERRELL, O. C. F.. Fundamentos de marketing. São Paulo: Cengage Learning, 2015.

RODRIGUES, A.. Metodologia científica. São Paulo: Avercamp, 2006

PEREIRA, G. R. B.. Planejamento Estratégico em Marketing. Natal: UnP, 2012

SANTINI JUNIOR, N.. Princípios e ferramentas da estratégia empresarial. São Paulo: Atlas, 2011.

TAKAHASHI, A. R. W.; BULGACOV, S.; SEMPREBON, E.; GIACOMINI, M. M.. Capacidades dinâmicas, capacidade de marketing e desempenho organizacional. BBR, Braz. Bus. Rev., v.14, n.5, p.466-478, 2017.

VARADARAJAN, R.. Strategic marketing and marketing strategy: Domain, definition, fundamental issues and foundational premises. Journal of the Academy of Marketing Science, v.38, n.2, p.119-140, 2010.

VARGAS, H. C.; MONTOYA, N. P.; ESTRADA, S.. Incidencia de la innovación en marketing en el rendimiento empresarial: una aplicación basada en modelamiento con ecuaciones estructurales. Estudios Gerenciales, v.36, n.154, 2020.

YIN, R. K.. Estudo de caso: planejamento e métodos. Porto Alegre: Bookman, 2005.

A CBPC - Companhia Brasileira de Produção Científica (CNPJ: 11.221.422/0001-03) detém os direitos materiais desta publicação. Os direitos referem-se à publicação do trabalho em qualquer parte do mundo, incluindo os direitos às renovações, expansões e disseminações da contribuição, bem como outros direitos subsidiários. Todos os trabalhos publicados eletronicamente poderão posteriormente ser publicados em coletâneas impressas sob coordenação da Sustenere Publishing, da Companhia Brasileira de Produção Científica e seus parceiros autorizados. Os (as) autores (as) preservam os direitos autorais, mas não têm permissão para a publicação da contribuição em outro meio, impresso ou digital, em português ou em tradução. 